\title{
Ultrasound-Guided Transversus Abdominis Plane Block for Analgesia in Laparoscopic Cholecystectomy: A Systematic Review and Meta-Analysis
}

\author{
Ke Peng Fu-hai Ji Hua-yue Liu Shao-ru Wu \\ Department of Anesthesiology, First Affiliated Hospital of Soochow University, Suzhou, China
}

\section{Key Words}

Transversus abdominis plane block · Laparoscopic

cholecystectomy · Ultrasound · Analgesia

\begin{abstract}
Objectives: To evaluate the analgesic efficacy of ultrasound-guided transversus abdominis plane (TAP) block for patients undergoing laparoscopic cholecystectomy (LC). Materials and Methods: A systematic literature search was conducted to identify randomized controlled trials that compared ultrasound-guided TAP block with control for analgesia in adult patients undergoing LC. The original data were pooled for the meta-analysis using Review Manager 5 . The main outcomes included postoperative pain intensity, opioid consumption, and adverse events. Out of a total of 77 trials, 7 were included. Results: Compared with control, ultrasound-guided TAP block reduced the following: (1) postoperative pain intensity (visual analog scale: $0-10$ ) both at rest and on movement at $0,2,4,8$, and $24 \mathrm{~h}$ (at rest: mean difference, $\mathrm{MD}_{0 \mathrm{~h}}=-2.19,95 \%$ confidence interval, $\mathrm{Cl}:-3.46$ to $-0.91, \mathrm{p}=0.0008$; on movement: $\mathrm{MD}_{0 \mathrm{~h}}=-2.67,95 \% \mathrm{Cl}:-3.86$ to $\left.-1.48, \mathrm{p}<0.0001\right)$; (2) intraoperative fentanyl consumption (MD $=-27.85 \mu \mathrm{g}, 95 \% \mathrm{Cl}$ : -44.91 to $-10.79, p=0.001$ ), and (3) morphine consump-
\end{abstract}

tion in the recovery room $(\mathrm{MD}=-1.57 \mathrm{mg}, 95 \% \mathrm{Cl}:-3.0$ to $-0.14, p=0.03$ ) and $0-24 h$ postoperatively. Fewer patients required analgesics in the recovery room when receiving TAP blocks (risk ratio, $\mathrm{RR}=0.35,95 \% \mathrm{Cl}: 0.20$ to $0.62, \mathrm{p}=$ $0.0003)$. TAP blocks also reduced postoperative nausea and vomiting ( $\mathrm{RR}=0.48,95 \% \mathrm{Cl}: 0.28$ to $0.81, \mathrm{p}=0.006)$. None of the studies reported symptoms of local anesthetic toxicity. Conclusions: In this study, the ultrasound-guided TAP block was an effective strategy for analgesia in patients undergoing $L C$.

ㄷ) 2016 S. Karger AG, Basel

\section{Introduction}

Laparoscopic cholecystectomy (LC) is the gold standard for the treatment of symptomatic gallbladder diseases such as cholecystitis and cholelithiasis $[1,2]$. Although it is considered to be minimally invasive, pain intensity in the early postoperative period is still significant $[3,4]$. Proper pain control is essential for optimizing clinical outcomes and earlier ambulation after surgery. Traditional pain management with opioids increases the incidence of side effects such as excessive sedation and postoperative nausea and vomiting (PONV). Multimodal

\begin{tabular}{ll}
\hline KARGER & $\begin{array}{l}\text { ( ) 2016 S. Karger AG, Basel } \\
1011-7571 / 16 / 0253-0237 \$ 39.50 / 0 \quad \text { Karger }\end{array}$ \\
$\begin{array}{l}\text { E-Mail karger@karger.com } \\
\text { www.karger.com/mpp }\end{array}$ & $\begin{array}{l}\text { Thisis an Open Access article licensed under the terms of the } \\
\text { Creative Commons Attribution-NonCommercial 3.0 Un- } \\
\text { ported license (CC BY-NC) (www.karger.com/OA-license), } \\
\text { applicable to the online version of the article only. Distribu- } \\
\text { tion permitted for non-commercial purposes only. }\end{array}$
\end{tabular}

Ke Peng

Department of Anesthesiology

First Affiliated Hospital of Soochow University

188 Shizi Street, Suzhou 215006 (China)

E-Mail pengke0422@163.com 
Fig. 1. Flowchart of included and excluded articles.

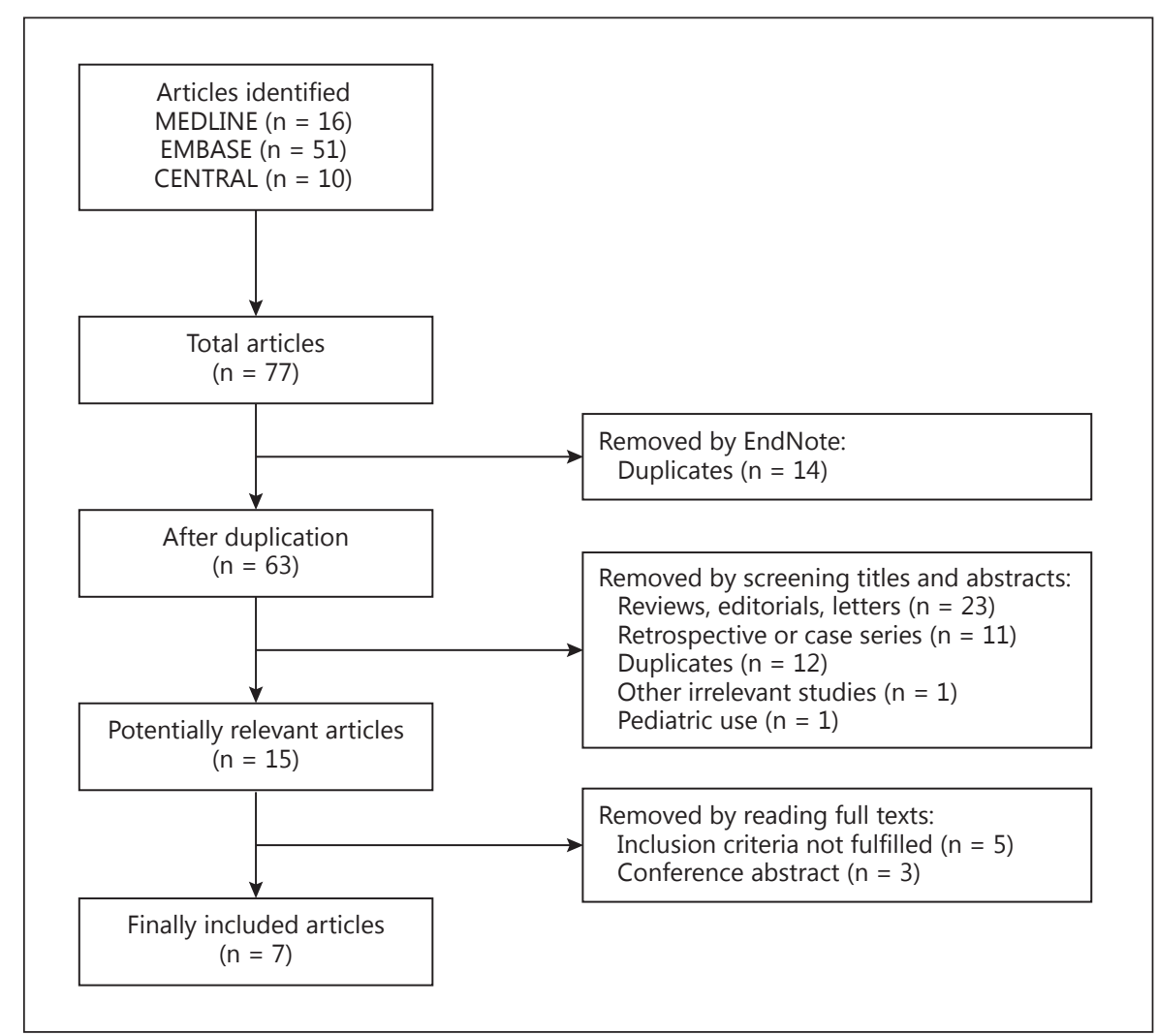

analgesia strategies with different classes of analgesics or local anesthetics may enhance pain relief and reduce side effects after surgery [5].

The transversus abdominis plane (TAP) block, a newer regional nerve blockade, has been used as part of a multimodal strategy to optimize postoperative pain control. With the guidance of ultrasound or an anatomical landmark, local anesthetic is injected into the neurovascular plane of the abdominal wall where the nerves from T6 to L1 are located [6]. Although there are several systematic reviews evaluating the effectiveness of TAP block, the various surgical procedures produced different pain intensities [7-11]. Also, the problem with different surgical populations is that the results may not be applied to the specific population undergoing LC. Moreover, the spread of local anesthetic given by the landmark approach is unlikely to provide the necessary sensory blockade over the incision area in cholecystectomy [12]. Therefore, this meta-analysis was conducted to systematically collect current data and compare the effects of ultrasound-guided TAP block on postoperative analgesia outcomes with control for adult patients undergoing LC.

\section{Materials and Methods}

This systematic review and meta-analysis was performed according to the current recommendations of the Cochrane Collaboration and reported following the Preferred Reporting Items for Systematic Reviews and Meta-Analyses (PRISMA) guidelines [13].

Search Strategy and Study Selection

Three authors (K.P., F.J., and H.L.) independently searched MEDLINE, EMBASE, and Cochrane Central Register of Controlled Trials (CENTRAL) databases using the following strategies: (a) transversus abdominis plane block AND laparoscopic cholecystectomy for the MEDLINE search; (b) 'transversus abdominis plane block'/exp OR 'transversus abdominis plane block' AND ('laparoscopic cholecystectomy'/exp OR 'laparoscopic cholecystectomy') AND [humans]/lim for the EMBASE search, and (c) transversus abdominis plane block AND laparoscopic cholecystectomy Search ALL Text for the CENTRAL search. The last search was performed in February 2015.

No language or publication date restriction was used. Additional information was retrieved by reviewing the reference lists from the identified articles. The search results were collated and deduplicated in Endnote X7 (Thomson Reuters, New York, N.Y., USA). The titles and abstracts of potentially relevant studies were screened before the retrieval of the full texts. All three authors examined the full papers to determine which studies met the inclusion criteria. Disagreement about study selection was resolved by discussion and consensus with another author (S.W.). 
Table 1. Characteristics of included trials

\begin{tabular}{|c|c|c|c|c|}
\hline $\begin{array}{l}\text { First author } \\
\text { [Ref.], year }\end{array}$ & Group & Treatment & Anesthesia & Postoperative analgesia \\
\hline $\begin{array}{l}\text { Bhatia [17], } \\
2014\end{array}$ & $\begin{array}{l}\text { Control }(n=20) \\
\text { TAP block }(n=20) \\
\text { Subcostal TAP block } \\
(n=20)\end{array}$ & $\begin{array}{l}\text { Bilateral } 15 \mathrm{ml} \text { of } 0.375 \% \\
\text { ropivacaine } \\
\text { before extubation }\end{array}$ & $\begin{array}{l}\text { Propofol/morphine/ } \\
\text { nitrous oxide/ } \\
\text { isoflurane }\end{array}$ & $\begin{array}{l}\text { Acetaminophen } 1 \text { g, i.v., every } 6 \mathrm{~h} \text {, } \\
\text { tramadol } 2 \mathrm{mg} / \mathrm{kg} \text {, i.v., as an initial } \\
\text { dose and } 1 \mathrm{mg} / \mathrm{kg} \text { if needed }\end{array}$ \\
\hline $\begin{array}{l}\text { Shin [19], } \\
2014\end{array}$ & $\begin{array}{l}\text { Control }(\mathrm{n}=15) \\
\text { TAP block }(\mathrm{n}=15) \\
\text { Subcostal TAP block } \\
(\mathrm{n}=15)\end{array}$ & $\begin{array}{l}\text { Bilateral } 20 \mathrm{ml} \text { of } 0.375 \% \\
\text { ropivacaine } \\
\text { after induction }\end{array}$ & $\begin{array}{l}\text { Propofol/fentanyl/ } \\
\text { sevoflurane }\end{array}$ & $\begin{array}{l}\text { Fentanyl } 25 \mu \mathrm{g} \text {, i.v. }+ \text { ketorolac } \\
30 \mathrm{mg} \text { in the recovery room and } \\
\text { nalbuphine } 10 \mathrm{mg} \text { on the ward if } \\
\text { needed }\end{array}$ \\
\hline $\begin{array}{l}\text { Petersen [21], } \\
2012\end{array}$ & $\begin{array}{l}\text { Control }(\mathrm{n}=37) \\
\text { TAP block }(\mathrm{n}=37)\end{array}$ & $\begin{array}{l}\text { Bilateral } 20 \mathrm{ml} \text { of } 0.5 \% \\
\text { ropivacaine } \\
\text { after induction }\end{array}$ & $\begin{array}{l}\text { Propofol/remifentanil/ } \\
\text { sufentanil }\end{array}$ & $\begin{array}{l}\text { Oral acetaminophen } 1 \mathrm{~g} \text { and } \\
\text { ibuprofen } 400 \mathrm{mg} \text { every } 6 \mathrm{~h} \text {, } \\
\text { morphine } 2.5 \mathrm{mg} \text {, i.v., in the } \\
\text { recovery room and oral } \\
\text { ketobemidone } 2.5 \mathrm{mg} \text { on the ward } \\
\text { if needed }\end{array}$ \\
\hline $\begin{array}{l}\mathrm{Ra}[22] \\
2010\end{array}$ & $\begin{array}{l}\text { Control }(\mathrm{n}=18) \\
\text { TAP block } 0.25 \%(\mathrm{n}=18) \\
\text { TAP block } 0.5 \%(\mathrm{n}=18)\end{array}$ & $\begin{array}{l}\text { Bilateral } 15 \mathrm{ml} \text { of } 0.25 \% \\
\text { or } 0.5 \% \mathrm{~L} \text {-bupivacaine } \\
\text { after induction }\end{array}$ & $\begin{array}{l}\text { Midazolam/propofol/ } \\
\text { remifentanil }\end{array}$ & $\begin{array}{l}\text { Ketorolac } 30 \mathrm{mg} \text { and fentanyl } \\
20 \mu \mathrm{g} \text { in the recovery room if } \\
\text { needed, ketorolac } 30 \mathrm{mg} \text { every } 8 \mathrm{~h} \\
\text { on the ward }\end{array}$ \\
\hline
\end{tabular}

PCA = Patient-controlled analgesia.

\section{Inclusion and Exclusion}

Inclusion criteria were as follows: (a) design: randomized controlled trials; (b) population: adult surgical patients undergoing elective LC; (c) intervention: comparison of perioperative ultrasound-guided TAP blocks with an inactive (placebo or 'no treatment') control group, and (d) outcomes: postoperative pain intensity, opioid consumption and related adverse events.

Exclusion criteria were as follows: (a) comparison of perioperative TAP blocks with wound or port-site infiltration; (b) trials that did not report specific outcomes, and (c) unavailability of full text.

\section{Data Extraction}

Two review authors (K.P. and F.J.) independently extracted the following data from eligible studies: publication year, authors, number of patients, interventions, and outcomes. Corresponding authors were contacted for missing data when necessary. Disagreement about data extraction was resolved by discussion and consensus with other authors (H.L. and S.W.).

\section{Primary and Secondary Outcome Parameters}

Primary outcomes were postoperative pain intensity at rest and on movement. Pain intensity was rated with a visual analog scale (from 0 to 10 ) or a verbal rating scale (from 0 to 10 ) at 6 time points (postoperative $0,2,4,6,8$, and $24 \mathrm{~h}$ ).

Secondary outcomes were: (a) intraoperative fentanyl consumption; (b) morphine consumption in the recovery room; (c) morphine consumption during $0-24 \mathrm{~h}$ after surgery; (d) number of patients who needed analgesics in the recovery room, and (e) number of patients with PONV. Opioid consumption in the recovery room and during $0-24 \mathrm{~h}$ postoperatively was transformed to morphine-equivalent consumption using previously published equianalgesic conversion factors (morphine $10 \mathrm{mg}=$ tramadol 100 $\mathrm{mg}=$ meperidine $100 \mathrm{mg}=$ fentanyl $0.1 \mathrm{mg}$, i.v.) $[14,15]$.

\section{Risk of Bias Assessment}

Two authors (K.P. and H.L.) used the Cochrane Collaboration's tool to assess the risk of bias in each identified study [16]. This tool considered six different domains: (a) random sequence 
Table 2. Risk of bias of included trials

\begin{tabular}{|c|c|c|c|c|c|c|}
\hline Bhatia [17], 2014 & Low & Low & Unclear & Low & Low & Low \\
\hline Kokulu [18], 2014 & Low & Low & Unclear & Unclear & Unclear & Low \\
\hline Petersen [21], 2012 & Low & Low & Low & Low & Low & Low \\
\hline $\mathrm{Ra}[22], 2010$ & Unclear & Unclear & Low & Low & Unclear & Unclear \\
\hline El-Dawlatly [23], 2009 & Low & Low & Low & Unclear & Unclear & Low \\
\hline
\end{tabular}

generation (selection bias); (b) allocation concealment (selection bias); (c) blinding of participants and personnel (performance bias); (d) blinding of outcome assessment (detection bias); (e) incomplete outcome data (attrition bias), and (f) selective reporting (reporting bias). The estimated overall risk of bias for each trial was categorized as 'low', 'unclear', or 'high'. Disagreement about risk of bias assessment was resolved by discussion and consensus with other authors (F.J. and S.W.).

\section{Statistical Analysis}

Data were pooled if at least 2 trials were included for an outcome. Continuous outcomes are reported as weighted mean differences (MD) and 95\% confidence intervals (CI), while categorical outcomes are reported as risk ratios (RR). A p value $<0.05$ was considered statistically significant. Heterogeneity was assessed with the $\mathrm{I}^{2}$ test. For outcome data with evidence of low heterogeneity ( $\left.\mathrm{I}^{2} \leq 30 \%\right)$, a fixed-effect model was used; for outcome data with evidence of significant heterogeneity $\left(\mathrm{I}^{2}>30 \%\right)$, a randomeffect model was selected [15]. Subgroup analysis was performed according to the data of conventional or subcostal TAP blocks. Statistical analyses were performed with Review Manager 5.1 (Nordic Cochrane Center, Cochrane Collaboration, Copenhagen, Denmark).

\section{Results}

\section{Characteristics of Included Trials}

A total of 77 articles were relevant to the search terms, and 15 studies were potentially eligible for inclusion. After reading the full-text articles, 7 studies [17-23] covering 355 participants were finally included into this review. The flow diagram for the selection is shown in figure 1.

The characteristics of the included studies are shown in table 1. Of the 7 included studies, all were randomized controlled trials comparing perioperative ultrasoundguided TAP blocks with a control group. Six trials applied conventional TAP block techniques and 3 trials used subcostal TAP block. One study performed the TAP block before extubation, while the other 6 studies applied it after induction.

Risk assessment as recommended in the Cochrane Handbook is listed in table 2. Six included studies clearly reported the methods of randomization [17-21,23] and 3 detailed the methods of double blinding [17-21, 23]. Because of the small number of trials included, funnel plots for publication bias could not be reliably examined.

\section{Clinical Outcomes}

The main outcomes of pain intensity at rest and on movement at 6 different time points after surgery are reported in table 3. At all time points, significantly lower pain scores were reported by patients receiving TAP blocks compared with those receiving conventional treatment, except for the data at postoperative $6 \mathrm{~h}$. The $\mathrm{MD}_{\text {rest }}$ decreased from -2.19 (95\% CI: -3.46 to $-0.91, \mathrm{p}=0.0008$, $\left.\mathrm{I}^{2}=95 \%\right)$ at postoperative $0 \mathrm{~h}$ (fig. 2) to -0.49 (95\% CI: -0.95 to $\left.-0.03, \mathrm{p}=0.04, \mathrm{I}^{2}=79 \%\right)$ at postoperative $24 \mathrm{~h}$. The $\mathrm{MD}_{\text {movement }}$ decreased from -2.67 (95\% CI: -3.86 to $-1.48, \mathrm{p}<0.0001, \mathrm{I}^{2}=92 \%$ ) at postoperative $0 \mathrm{~h}$ (fig. 3 ) to -0.72 (95\% CI: -1.32 to $\left.-0.13, \mathrm{p}=0.02, \mathrm{I}^{2}=83 \%\right)$ at postoperative $24 \mathrm{~h}$.

All included studies reported data about opioid requirements [15-21]. Compared with patients in the control group, intraoperative fentanyl consumption $(\mathrm{MD}=$ $-27.85 \mu \mathrm{g}$, 95\% CI: -44.91 to $-10.79, \mathrm{p}=0.001, \mathrm{I}^{2}=96 \%$ ), morphine consumption in the recovery room ( $\mathrm{MD}=$ $-1.57 \mathrm{mg}, 95 \% \mathrm{CI}:-3.0$ to $-0.14, \mathrm{p}=0.03, \mathrm{I}^{2}=91 \%$; fig. 4), and morphine consumption during $0-24 \mathrm{~h}$ after surgery $(\mathrm{MD}=-9.16 \mathrm{mg}, 95 \% \mathrm{CI}:-14.09$ to $-4.24, \mathrm{p}=0.0003$, $\left.\mathrm{I}^{2}=59 \%\right)$ were significantly reduced in patients receiving TAP blocks. Additionally, there were fewer patients who 
Table 3. Pain intensity at rest and on movement at 6 different time points for the comparison of ultrasound-guided TAP block and control

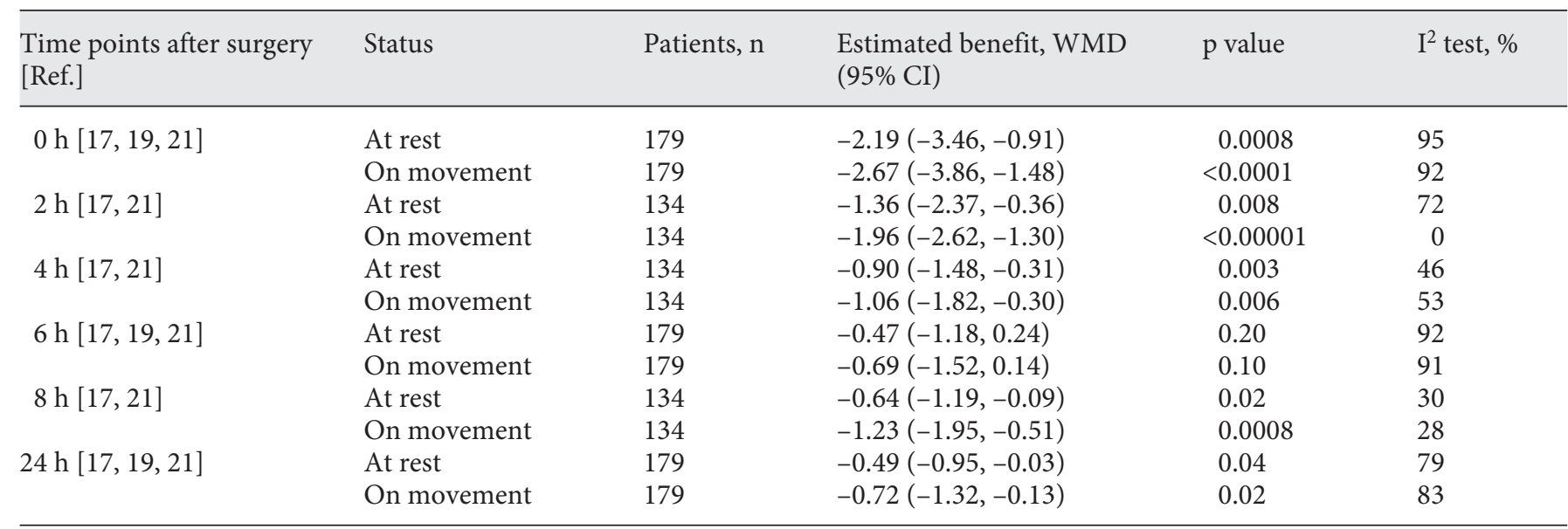

Pain intensity was scored with a visual analog scale or verbal rating scale, where $0=$ no pain and $10=$ the most severe pain imaginable. WMD = Weighted mean difference.

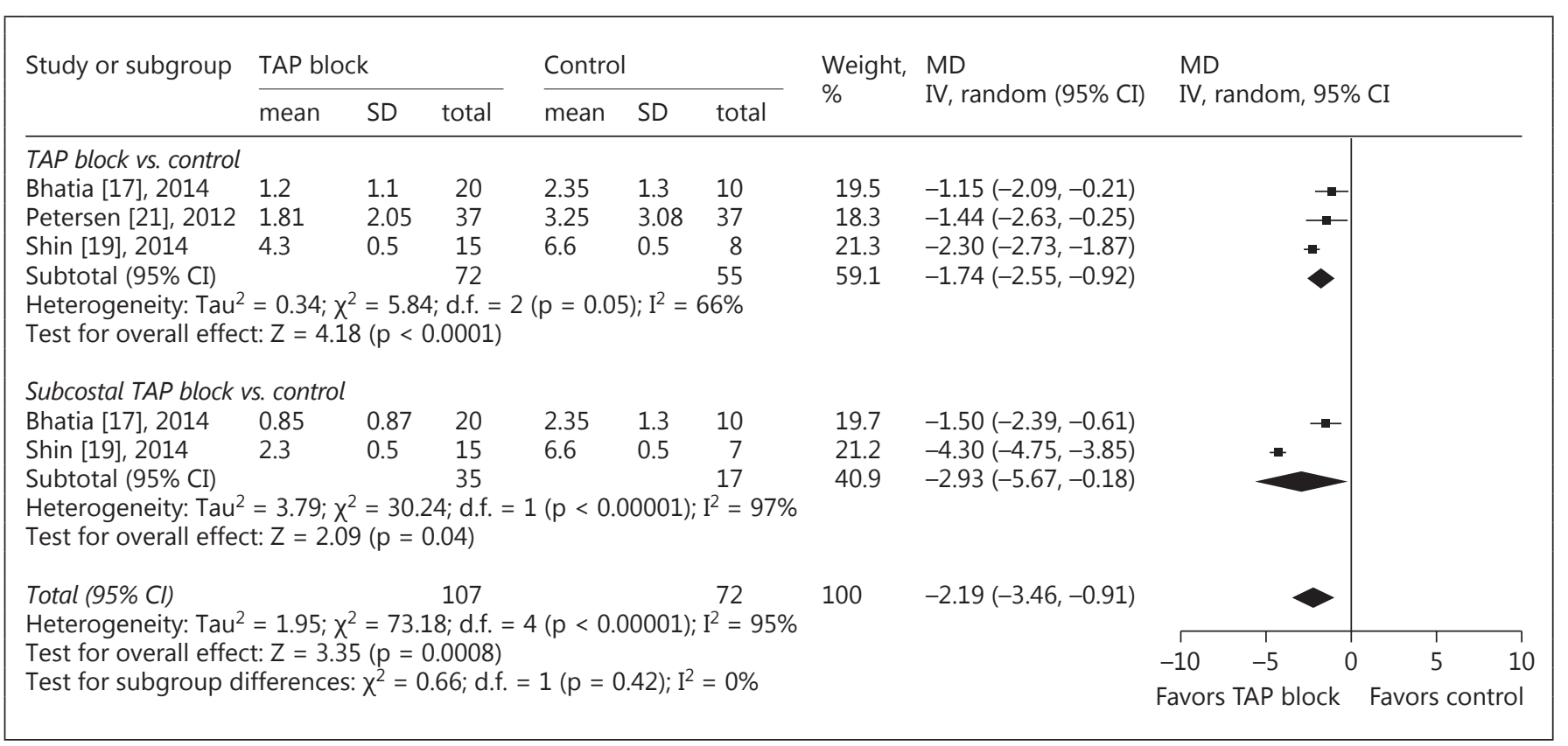

Fig. 2. TAP block vs. control for LC: pain intensity at rest at $0 \mathrm{~h}$ after operation. Pain intensity was scored with a visual analog scale or a verbal rating scale, where $0=$ no pain and $10=$ the most severe pain imaginable. IV $=$ Inverse variance.

needed analgesics in the recovery room when receiving TAP blocks ( $\mathrm{RR}=0.35,95 \% \mathrm{CI}: 0.20$ to $0.62, \mathrm{p}=0.0003$, $I^{2}=43 \%$; fig. 5).

Data reporting PONV are described in 4 trials $[15,17-$ 19]. There was a lower incidence of $\mathrm{PONV}(\mathrm{RR}=0.48$,
95\% CI: 0.28 to $\left.0.81, \mathrm{p}=0.006, \mathrm{I}^{2}=0 \%\right)$ in patients receiving TAP blocks compared with those in the control group (fig. 6). None of the studies reported symptoms of local anesthetic toxicity. 


\begin{tabular}{|c|c|c|c|c|c|c|c|c|c|c|}
\hline \multirow[t]{2}{*}{ Study or subgroup } & \multicolumn{3}{|c|}{ TAP block } & \multicolumn{3}{|c|}{ Control } & \multirow{2}{*}{$\begin{array}{l}\text { Weight, } \\
\%\end{array}$} & \multirow{2}{*}{$\begin{array}{l}\text { MD } \\
\text { IV, random (95\% CI) }\end{array}$} & \multirow{2}{*}{\multicolumn{2}{|c|}{$\begin{array}{l}\text { MD } \\
\text { IV, random, 95\% CI }\end{array}$}} \\
\hline & mean & SD & total & mean & SD & total & & & & \\
\hline Bhatia [17], 2014 & 2 & 1.4 & 20 & 3.4 & 1.5 & 10 & 18.8 & $-1.40(-2.51,-0.29)$ & $\rightarrow$ & \\
\hline Petersen [21], 2012 & 1.86 & 2.13 & 37 & 3.99 & 3.12 & 37 & 18.3 & $-2.13(-3.35,-0.91)$ & $\rightarrow-$ & \\
\hline Shin [19], 2014 & 4.7 & 0.6 & 15 & 7.5 & 0.5 & 8 & 21.8 & $-2.80(-3.26,-2.34)$ & $=$ & \\
\hline \multicolumn{11}{|c|}{ Subcostal TAP block vs. control } \\
\hline Bhatia [17], 2014 & 1.3 & 1 & 20 & 3.4 & 1.5 & 10 & 19.3 & $-2.10(-3.13,-1.07)$ & $\rightarrow-$ & \\
\hline Shin [19], 2014 & 2.9 & 0.6 & 15 & 7.5 & 0.5 & 7 & 21.8 & $-4.60(-5.08,-4.12)$ & 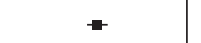 & \\
\hline \multicolumn{11}{|c|}{ Heterogeneity: $\mathrm{Tau}^{2}=1.64 ; \chi^{2}=52.78 ;$ d.f. $=4(\mathrm{p}<0.00001) ; \mathrm{I}^{2}=92 \%$} \\
\hline \multicolumn{7}{|c|}{ Test for overall effect: $Z=4.39(p<0.0001)$} & \multicolumn{4}{|c|}{-10} \\
\hline \multicolumn{7}{|c|}{ Test for subgroup differences: $\chi^{2}=0.77 ;$ d.f. $=1(p=0.38) ; I^{2}=0 \%$} & \multicolumn{4}{|c|}{ Favors TAP block Favors control } \\
\hline
\end{tabular}

Fig. 3. TAP block vs. control for LC: pain intensity on movement at $0 \mathrm{~h}$ after operation. Pain intensity was scored with a visual analog scale or verbal rating scale, where $0=$ no pain and $10=$ the most severe pain imaginable. IV $=$ Inverse variance.

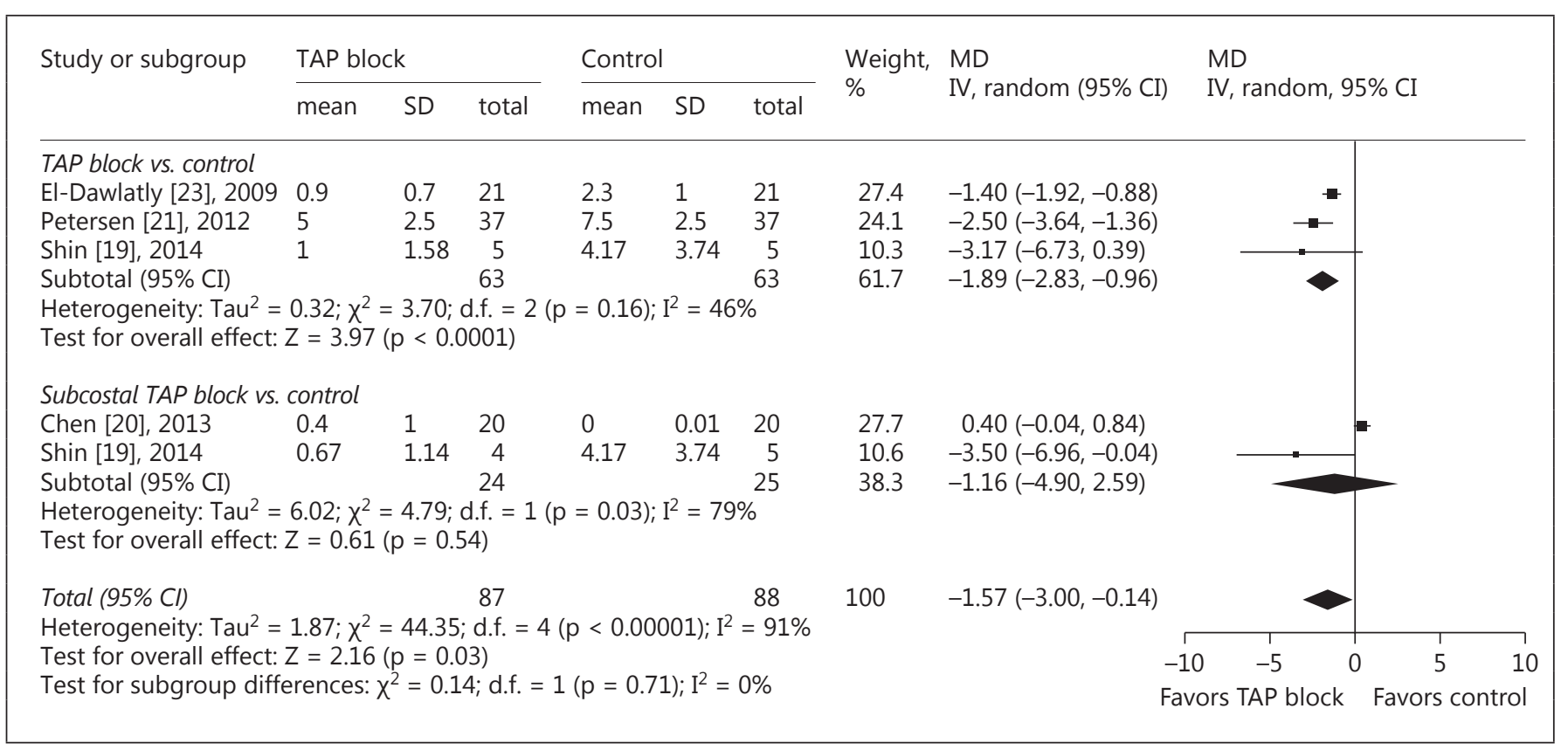

Fig. 4. TAP block vs. control for LC: morphine consumption in the recovery room. IV = Inverse variance. 


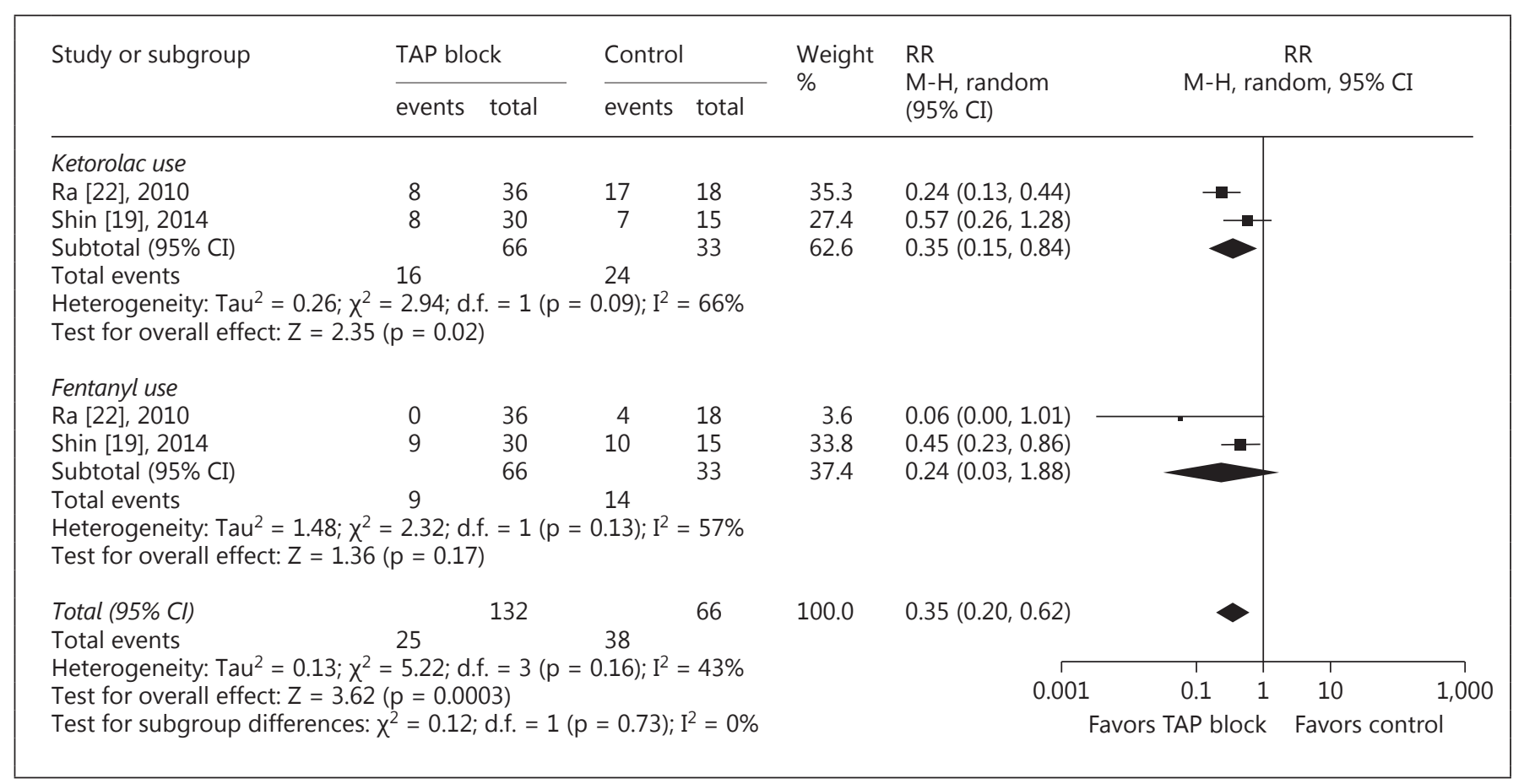

Fig. 5. TAP block vs. control for LC: analgesic use in the recovery room. M-H = Mantel-Haenszel.

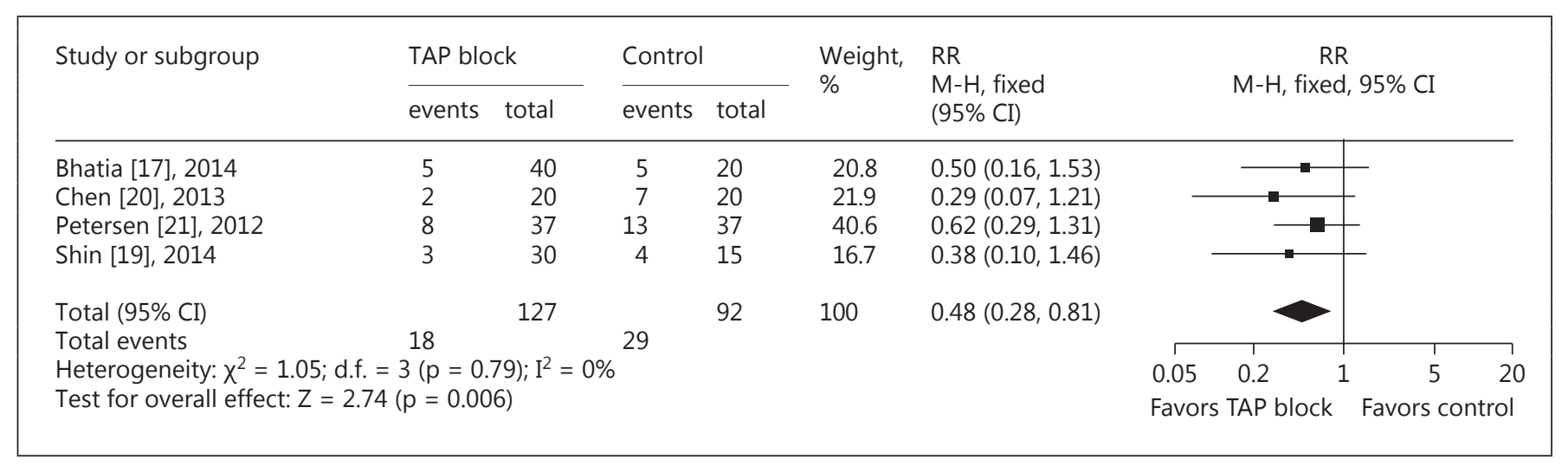

Fig. 6. TAP block vs. control for LC: PONV. M-H = Mantel-Haenszel.

\section{Discussion}

This meta-analysis revealed that ultrasound-guided TAP blocks lead to lower postoperative pain intensity at rest and on movement up to $24 \mathrm{~h}$ postoperatively for patients undergoing LC. Intra- and postoperative opioid consumption were also significantly reduced. Furthermore, it was shown that there was a significant reduction in PONV when a TAP block was performed. None of the included studies reported on complications related to TAP block.

\section{Pain after LC and Ultrasound-Guided TAP Block}

Pain is most severe during the first $24 \mathrm{~h}$ postoperatively in patients who undergo LC, and the port sites are the most painful regions [24]. Pain after LC consists mainly of two parts: visceral pain due to the trauma of gallbladder resection and parietal pain caused by skin in- 
cision. Bisgaard et al. [25] reported that incisional pain dominated in incidence and intensity compared with visceral pain after LC. Therefore, analgesic studies should focus on reduction of incisional pain to optimize the postoperative pain control in these patients.

The TAP block, a regional anesthetic technique that blocks abdominal wall somatic afferent nerves, may play an important role in multimodal pain therapy. The blind technique based on an anatomical landmark may cause inappropriate block and even injury to the abdominal viscera such as intestinal puncture and liver injury [26, 27]. In recent years, there has been growing interest in the clinical use of ultrasound which can provide visualization and improve accuracy. Thus, the quality of nerve blockade can be enhanced with the guidance of ultrasound. In this meta-analysis, all included studies performed ultrasound-guided TAP blocks, which could help to reduce the possible bias caused by the differences between ultrasound and landmark approaches.

The conventional method of ultrasound-guided TAP block is the posterior approach. Recently, the subcostal TAP block has been reported to provide effective analgesia for upper abdominal incisions [28]. Studies showed that the subcostal technique can provide sensory block of the T7 to T12 nerves while the TAP block involves the T10 to L1 nerves $[29,30]$. Thus, the subcostal TAP block could provide better analgesia for surgery on the upper abdominal wall. As only 2 studies in this meta-analysis compared the effects of subcostal TAP block with those of posterior TAP block, the evidence supporting the superiority of the subcostal approach is limited.

Local anesthetic infiltration of trocar insertion sites, which is a common practice for LC, had been shown to decrease postoperative pain and opioid requirements [31]. It is worthwhile to compare the analgesic effects of TAP block with those of local port infiltration for patients undergoing LC. However, only 2 published studies focused on this comparison, and the results were inconclusive $[32,33]$. Therefore, more studies are needed to investigate the superiority of the TAP block or local port infiltration.

\section{Analgesic Effects and Opioid-Related Side Effects}

The most important finding of the current meta-analysis was the significant effect of TAP block on postoperative pain outcomes for $\mathrm{LC}$, including reduced pain intensity and opioid consumption. Consequently, opioidrelated side effects such as PONV can be prevented. To the best of our knowledge, this is the first study that specifically focused on the efficacy of TAP block for LC pro- cedures rather than previous analyses that evaluated the effect of the TAP block on abdominal surgery [7-11] or Cesarean delivery $[34,35]$. The current data showed that pain scores both at rest and on movement were reduced up to postoperative $24 \mathrm{~h}$ in patients receiving TAP blocks compared with those receiving conventional treatment, except for the data at postoperative $6 \mathrm{~h}$. However, significant heterogeneity was found in most findings regarding pain outcomes, suggesting that these results still need to be treated with caution. The study of Bhatia et al. [17] performed TAP block postoperatively while the other studies had the block performed preoperatively, which may have contributed to the heterogeneity.

\section{Local Anesthetic Toxicity}

It had been reported that the effect of TAP block lasted up to $48 \mathrm{~h}$ postoperatively, which might be due to the slow clearance of local anesthetics injected into the neurovascular plane of the abdominal wall where relatively fewer blood vessels are located [36, 37]. As a result, the risk of systemic local anesthetic toxicity caused by TAP block can be reduced compared with other peripheral nerve block procedures. However, mild neurological symptoms associated with higher plasma local anesthetic concentrations cannot be detected under general anesthesia. Recently, there was a report [38] about convulsions in 2 patients after bilateral ultrasound-guided TAP blocks for Cesarean analgesia, indicating that the risk of systemic toxicity after this procedure remains unknown in specific populations. Therefore, safety concerns should not be a major barrier to performing TAP blocks for various surgical procedures as long as optimized local anesthetic dose regimens are selected.

\section{Limitations}

There were several limitations to this meta-analysis. First, only a small number of studies were included, and the sample sizes were relatively small. Second, the local anesthetics used in the TAP blocks varied, and the recommended doses and volumes of local anesthetics are not yet established. Third, the calculations of morphine equivalents may have introduced bias. Fourth, although the type of surgical procedure was limited in LC, significant heterogeneities were observed in some analyses, including pain intensity and morphine-equivalent consumption; therefore, these results must be evaluated with caution. Fifth, because of the small number of trials included, funnel plots for publication bias could not be reliably examined. Finally, there is a lack of long-term data to evaluate the effects of the TAP blocks on clinical outcomes such as 
chronic pain. In the future, the optimal dose and concentration of injected local anesthetics need to be investigated in larger outcome studies.

\section{Conclusions}

In this meta-analysis it was shown that ultrasoundguided TAP block can lead to superior analgesia, significant opioid sparing, and less opioid-related side effects in patients undergoing LC compared with those receiving conventional treatment alone. Ultrasound-guided TAP block may have an important role in multimodal pain therapy. More studies are required to investigate the optimal dose and concentration of injected local anesthetics and long-term outcomes in these patients.

\section{Disclosure Statement}

The authors have no conflicts of interest to declare.

\section{References}

1 Bucher P, Pugin F, Buchs NC, et al: Randomized clinical trial of laparoendoscopic singlesite versus conventional laparoscopic cholecystectomy. Br J Surg 2011;98:1695-702.

2 Keus F, de Jong JA, Gooszen HG, et al: Laparoscopic versus open cholecystectomy for patients with symptomatic cholecystolithiasis. Cochrane Database Syst Rev 2006; 18:CD006231.

3 Bisgaard T, Klarskov B, Kehlet H, et al: Preoperative dexamethasone improves surgical outcome after laparoscopic cholecystectomy: a randomized double-blind placebo-controlled trial. Ann Surg 2003;238:651-660.

4 Barczynski M, Herman RM: A prospective randomized trial on comparison of low-pressure and standard-pressure pneumoperitoneum for laparoscopic cholecystectomy. Surg Endosc 2003; 17:533-538.

-5 Buvanendran A, Kroin JS: Multimodal analgesia for controlling acute postoperative pain Curr Opin Anaesthesiol 2009;22:588-593.

6 Rozen WM, Tran TM, Ashton MW, et al: Refining the course of the thoracolumbar nerves: a new understanding of the innervation of the anterior abdominal wall. Clin Anat 2008;21: 325-333.

7 De Oliveira GS Jr, Castro-Alves LJ, Nader A, et al: Transversus abdominis plane block to ameliorate postoperative pain outcomes after laparoscopic surgery: a meta-analysis of randomized controlled trials. Anesth Analg 2014; 118:454-463.

8 Champaneria R, Shah L, Geoghegan J, et al: Analgesic effectiveness of transversus abdominis plane blocks after hysterectomy: a metaanalysis. Eur J Obstet Gynecol Reprod Biol 2013;166:1-9.

9 Johns N, O’Neill S, Ventham NT, et al: Clinical effectiveness of transversus abdominis plane (TAP) block in abdominal surgery: a systematic review and meta-analysis. Colorectal Dis 2012;14:e635-e642.
10 Siddiqui MR, Sajid MS, Uncles DR, et al: A meta-analysis on the clinical effectiveness of transversus abdominis plane block. J Clin Anesth 2011;23:7-14.

11 Charlton S, Cyna AM, Middleton P, et al: Perioperative transversus abdominis plane (TAP) blocks for analgesia after abdominal surgery. Cochrane Database Syst Rev 2010; 12:CD007705.

12 Carney J, Finnerty O, Rauf J, et al: Studies on the spread of local anaesthetic solution in transversus abdominis plane blocks. Anaesthesia 2011;66:1023-1030.

13 Moher D, Liberati A, Tetzlaff J, et al: Preferred reporting items for systematic reviews and meta-analyses: the PRISMA statement. BMJ 2009;339:b2535.

14 Von Korff M, Saunders K, Thomas Ray G, et al: De facto long-term opioid therapy for noncancer pain. Clin J Pain 2008;24:521-527.

$\checkmark 15$ Peng K, Liu HY, Wu SR, et al: Effects of combining dexmedetomidine and opioids for postoperative intravenous patient-controlled analgesia: a systematic review and meta-analysis. Clin J Pain 2015;31:1097-1104.

16 Higgins J, Green S: Cochrane Handbook for Systematic Reviews of Interventions, version 5.1.0. The Cochrane Collaboration, 2011. www.cochrane-handbook.org.

17 Bhatia N, Arora S, Jyotsna W, et al: Comparison of posterior and subcostal approaches to ultrasound-guided transverse abdominis plane block for postoperative analgesia in laparoscopic cholecystectomy. J Clin Anesth 2014;26:294-299.

18 Kokulu S, Bakı ED, Kaçar E, et al: Effect of transversus abdominis plane block on cost of laparoscopic cholecystectomy anesthesia. Med Sci Monit 2014;20:2783-2787.

19 Shin HJ, Oh AY, Baik JS, et al: Ultrasoundguided oblique subcostal transversus abdominis plane block for analgesia after laparoscopic cholecystectomy: a randomized, controlled, observer-blinded study. Minerva Anestesiol 2014;80:185-193.
20 Chen CK, Tan PC, Phui VE, et al: A comparison of analgesic efficacy between oblique subcostal transversus abdominis plane block and intravenous morphine for laparoscopic cholecystectomy. A prospective randomized controlled trial. Korean J Anesthesiol 2013;64: 511-516.

21 Petersen PL, Stjernholm P, Kristiansen VB, et al: The beneficial effect of transversus abdominis plane block after laparoscopic cholecystectomy in day-case surgery: a randomized clinical trial. Anesth Analg 2012;115:527533.

22 Ra YS, Kim CH, Lee GY, et al: The analgesic effect of the ultrasound-guided transverse abdominis plane block after laparoscopic cholecystectomy. Korean J Anesthesiol 2010;58: 362-368.

23 El-Dawlatly AA, Turkistani A, Kettner SC, et al: Ultrasound-guided transversus abdominis plane block: description of a new technique and comparison with conventional systemic analgesia during laparoscopic cholecystectomy. Br J Anaesth 2009;102:763-767.

24 Wills VL, Hunt DR: Pain after laparoscopic cholecystectomy. Br J Surg 2000;87:273-284.

25 Bisgaard T, Klarskov B, Rosenberg J, et al: Characteristics and prediction of early pain after laparoscopic cholecystectomy. Pain 2001;90:261-269.

26 Jöhr M, Sossai R: Colonic puncture during ilioinguinal nerve block in a child. Anesth Analg 1999;88:1051-1052.

27 Farooq M, Carey M: A case of liver trauma with a blunt regional anesthesia needle while performing transversus abdominis plane block. Reg Anesth Pain Med 2008;33:274275 .

28 Hebbard PD, Barrington MJ, Vasey C: Ultrasound-guided continuous oblique subcostal transversus abdominis plane blockade: description of anatomy and clinical technique. Reg Anesth Pain Med 2010;35:436-441. 
29 Tran TM, Ivanusic JJ, Hebbard P, et al: Determination of spread of injectate after ultrasound-guided transversus abdominis plane block: a cadaveric study. Br J Anaesth 2009; 102:123-127.

30 Barrington MJ, Ivanusic JJ, Rozen WM, et al: Spread of injectate after ultrasound-guided subcostal transversus abdominis plane block: a cadaveric study. Anaesthesia 2009;64:745750 .

-31 Bisgaard T: Analgesic treatment after laparoscopic cholecystectomy: a critical assessment of the evidence. Anesthesiology 2006;104: 835-846.

-32 Ortiz J, Suliburk JW, Wu K, et al: Bilateral transversus abdominis plane block does not decrease postoperative pain after laparoscop- ic cholecystectomy when compared with local anesthetic infiltration of trocar insertion sites. Reg Anesth Pain Med 2012;37:188-192.

33 Tolchard S, Davies R, Martindale S: Efficacy of the subcostal transversus abdominis plane block in laparoscopic cholecystectomy: comparison with conventional port-site infiltration. J Anaesthesiol Clin Pharmacol 2012;28: 339-343.

34 Abdallah FW, Halpern SH, Margarido CB: Transversus abdominis plane block for postoperative analgesia after Caesarean delivery performed under spinal anaesthesia? A systematic review and meta-analysis. Br J Anaesth 2012;109:679-687.

35 Mishriky BM, George RB, Habib AS: Transversus abdominis plane block for analgesia af- ter Cesarean delivery: a systematic review and meta-analysis. Can J Anaesth 2012;59:766778.

36 O'Donnell BD, McDonnell JG, McShane AJ: The transversus abdominis plane (TAP) block in open retropubic prostatectomy. Reg Anesth Pain Med 2006;31:91.

37 McDonnell JG, Curley G, Carney J, et al: The analgesic efficacy of transversus abdominis plane block after Cesarean delivery: a randomized controlled trial. Anesth Analg 2008; 106:186-191.

38 Weiss E, Jolly C, Dumoulin JL, Meftah RB, et al: Convulsions in 2 patients after bilateral ultrasound-guided transversus abdominis plane blocks for Cesarean analgesia. Reg Anesth Pain Med 2014;39:248-251. 